\title{
BMJ Open Telemedicine in primary healthcare for the quality of care in times of COVID-19: a scoping review protocol
}

Cícera Renata Diniz Vieira Silva (D) , ${ }^{1}$ Rayssa Horácio Lopes, ${ }^{2}$
Osvaldo de Goes Bay Júnior, ${ }^{2}$ Miguel Fuentealba-Torres, ${ }^{3}$
Ricardo Alexandre Arcêncio, ${ }^{4}$ Severina Alice da Costa Uchôa ${ }^{5}$

To cite: Silva CRDV, Lopes RH, Júnior OdGB, et al. Telemedicine in primary healthcare for the quality of care in times of COVID-19: a scoping review protocol. BMJ Open 2021;11:e046227. doi:10.1136/ bmjopen-2020-046227

- Prepublication history and additional supplemental material for this paper are available online. To view these files, please visit the journal online. To view these files, please visit the journal online (http://dx.doi org/10.1136/bmjopen-2020046227).

Received 25 0ctober 2020 Accepted 17 June 2021

\section{Check for updates}

(c) Author(s) (or their employer(s)) 2021. Re-use permitted under CC BY-NC. No commercial re-use. See rights and permissions. Published by BMJ.

${ }^{1}$ Postgraduate in Health Sciences, Federal University of Rio Grande do Norte, Natal, Brazil

${ }^{2}$ Postgraduate in Collective Health, Federal University of Rio Grande do Norte, Natal, Brazil

${ }^{3}$ Universidad de los Andes, Chile, Santiago, Chile

${ }^{4}$ Department of MaternalInfant Nursing and Public Health, University of São Paulo at Ribeirão Preto College of Nursing, Ribeirão Preto, Brazil ${ }^{5}$ Department of Collective Health, Federal University of Rio Grande do Norte, Natal, Brazil

Correspondence to Dr Cícera Renata Diniz Vieira Silva;

renatadiniz_enf@yahoo.com.br

\section{ABSTRACT}

Introduction Telemedicine gained strength in primary healthcare (PHC) during the COVID-19 pandemic. Thus, there is a need to know its scope, technologies used and impacts on people's health. This study will map telemedicine use in PHC around the world and its impacts on quality of care in the context of the COVID-19 pandemic.

Methods This is a scoping review protocol developed according to Arksey and O'Malley and Levac et al, based on the Joanna Briggs Institute manual, and guided by the Preferred Reporting Items for Systematic Reviews and Meta-Analyses Extension for Scoping Reviews (PRISMA-ScR). The records will be mapped in the following multidisciplinary health sciences databases: Virtual Health Library, PubMed, Scopus, Web of Science, CINAHL and Embase. Searches will also be conducted on Google Scholar, preprint repositories and specific COVID-19 databases (grey literature). Quantitative data will be analysed using descriptive statistics, while thematic analysis will be performed for qualitative data. Preliminary findings will be presented to stakeholders to identify missing studies and develop effective dissemination strategies.

Ethics and dissemination Results will be disseminated through publication in an open access scientific journal, scientific events, and academic and community newspapers. Ethical approval was obtained due to stakeholder consultation, but will not involve the direct participation of patients. Link to the protocol record in the Open Science Framework (OSF) (osf.io/q94en).

\section{INTRODUCTION}

COVID- $19,{ }^{1}$ caused by the SARS-CoV- $2,{ }^{2}$ was first reported in December 2019 in China. This disease triggered a public health emergency, ${ }^{3}$ leading the WHO to declare a pandemic situation. ${ }^{4}$ On 15 March 2021, the number of confirmed cases and deaths worldwide surpassed 119 and 2.6 million, respectively. ${ }^{5}$ Although the United Nations, WHO and Pan American Health Organization are working hard to obtain more information to combat the disease, they are still limited, and

\section{Strengths and limitations of this study}

- This scoping review will be the first to explore information and communication technology types used in telemedicine and their impact on quality of care in primary healthcare $(\mathrm{PHC})$ in the context of the COVID-19 pandemic.

- Geographical mapping of studies will show the global panorama of telemedicine use.

- Searches will be broad, including six peer-reviewed databases and the grey literature.

- The recent increase in telemedicine in PHC due to COVID-19 may be a limiting factor for consistent scientific publications.

- The large number of publications in the grey literature may be an important study limitation.

a greater level of knowledge is needed in all scientific areas. ${ }^{6}$

Following WHO recommendations, several countries have implemented quarantines, ${ }^{7}$ social distancing and mandatory home confinement. ${ }^{8}$ These measures have encouraged new technologies to respond to primary healthcare (PHC) demand. A tool that has been used is telemedicine, which has become a strategy to maintain assistance ${ }^{9-12}$ and guarantee admissibility and quality of care. ${ }^{13}$

The WHO adopted telemedicine or telehealth to define healthcare support using information and communication technologies (ICTs) ${ }^{14}{ }^{15}$ in situations in which distance and/or geographical barriers hinder healthcare services. ${ }^{14}$ ICTs (ie, internet, cell phones, computers or satellite TV) make communication flows between healthcare professionals and patients more effective; thus, enabling real-time assistance. ${ }^{16}$ Also, ICTs offer relevant information related to asynchronous healthcare using electronic portals or other virtual resources, such as email, text messages and mobile phone applications. ${ }^{16}$ 
Telemedicine use during the COVID-19 pandemic is occurring on large a scale and speed, becoming an efficient strategy to face PHC demand. ${ }^{17}$ This technology contributes to quality of healthcare services in PHC and strengthens monitoring, surveillance and detection of new COVID-19 cases. ${ }^{18}$ It also contributes to reducing patients' anxiety due to social isolation and maintaining contact between health professionals and patients with SARS-CoV-2; thus, allowing timely attention to most urgent cases ${ }^{19}$ and those with chronic diseases. ${ }^{20}$

Regarding the healthcare team, telemedicine has shown a positive impact on workloads, with a reduction in burnout syndrome, which has been recurrent since the beginning of the pandemic. ${ }^{21}$ This technology has also contributed to reducing fear of virus exposure by professionals, collaborating with quality of care offered, ${ }^{22}$ facilitating coordination between primary and secondary healthcare levels, ${ }^{22}$ and maximising patient and family well-being in the context of the pandemic. ${ }^{20}$

Quality of care has three dimensions: technical (action choice accuracy and production), interpersonal (social and psychological relationships between healthcare providers and users) and organisational (conditions in which services are offered, including continuity of care, coverage, action coordination, and service access and accessibility). ${ }^{23-25}$ In this study, technical dimension will represent the implementation of prevention and diagnosis measures and symptomatic treatment of mild COVID-19 cases in a timely manner (according to scientific protocols). Emotional support by healthcare providers to users and/or family members in a situation of social isolation will represent the interpersonal dimension, while continuity of care for patients without COVID-19 and monitoring and follow-up of COVID-19 cases will be considered the organisational dimension.

Given the importance of telemedicine in the current public health situation and the possibility of integrating this strategy after the pandemic, ${ }^{26}$ it is essential to expand the knowledge about telemedicine use in different countries, types of technologies used and impacts on quality of care in the PHC. Thus, this study will map telemedicine use in PHC around the world during the COVID-19 pandemic and its impacts on quality of care.

\section{METHODS}

This is a scoping review protocol, a type of study designed to answer broad research questions with less restrictive selection criteria. The inclusion of scientific articles and the grey literature aim to map key concepts, types of evidence and research gaps, systematically synthesising the existing knowledge on a topic. ${ }^{27} 28$ The study will be developed according to Arksey and $\mathrm{O}^{\prime} \mathrm{Malley}^{29}$ and Levac et $a l,{ }^{30}$ based on the Joanna Briggs Institute (JBI) manual, ${ }^{31}$ and guided by the Preferred Reporting Items for Systematic Reviews and Meta-Analyses Extension for Scoping Reviews (PRISMA-ScR). ${ }^{27}$

The following steps $^{29}{ }^{30}$ will guide this review: (1) formulation of research questions, (2) identification of relevant studies, (3) study selection, (4) data extraction and coding, (5) analysis and interpretation of results, (6) consultation with stakeholders.

\section{Step 1: formulation of research questions}

Three study questions were formulated and defined by consensus among authors using the PCC (PopulationConcept-Context) mnemonic ${ }^{31}$ and outcomes of interest (O) (table 1).

Concepts and definitions anchoring the research questions are described in table 2.

\section{Step 2: identification of relevant studies \\ Search strategy}

A previous exploratory search was conducted on PubMed and Virtual Health Library (VHL) databases to identify the main Medical Subject Headings (MeSH) and Descriptors in Health Sciences (DeCS) related to the topic. The search strategy was developed based on this preliminary search by combining descriptors and keywords using the Boolean operators AND and OR, and it will be adjusted according to each database. A complete search strategy for PubMed database is included ${ }^{27}$ in online supplemental appendix 1, and an example of searching for grey literature on Google Scholar in online supplemental appendix 2. The detailed search strategy for all data sources (ie, white and grey literature) will be attached to the final scoping review.

\section{Table 1 Scoping review questions}

\begin{tabular}{|c|c|c|c|c|}
\hline Question & Population (P) & Concept (C) & Context (C) & Outcomes of interest (0) \\
\hline $\begin{array}{l}\text { (3) What are the impacts of telemedicine on } \\
\text { quality of care in PHC in the context of the } \\
\text { COVID-19 pandemic? }\end{array}$ & & $\begin{array}{l}\text { Quality of } \\
\text { care }\end{array}$ & & $\begin{array}{l}\text { Impact of telemedicine on } \\
\text { patients' healthcare }\end{array}$ \\
\hline
\end{tabular}

ICT, information and communication technologies; PHC, primary healthcare. 
Table 2 Key concepts for research questions

\begin{tabular}{|c|c|}
\hline Concept & Definition \\
\hline Telemedicine & $\begin{array}{l}\text { Provision of healthcare services by health professionals in situations in which distance is a critical factor } \\
\text { using ICTs for research, continuing education of providers and health professionals, disease diagnosis, } \\
\text { treatment, prevention and evaluation to promote individual and community health. }{ }^{14} 15\end{array}$ \\
\hline $\begin{array}{l}\text { Information and } \\
\text { communication } \\
\text { technologies }\end{array}$ & $\begin{array}{l}\text { Integrated technological resources allowing access to information using telecommunication. It is the } \\
\text { product of telecommunication, information technology and electronic media and serves as regulatory tools. } \\
\text { It includes electronic devices used in healthcare, such as health information systems, electronic medical } \\
\text { records, electronic prescriptions, mobile health, computers, electronic portals, emails, messages, cell phone } \\
\text { applications, wearable devices (eg, smartwatches). }{ }^{163637}\end{array}$ \\
\hline Quality & $\begin{array}{l}\text { It has three dimensions: technical (action choice accuracy and production), interpersonal (social and } \\
\text { psychological relationships between healthcare providers and users) and organisational (conditions } \\
\text { in which services are offered, including continuity of care, coverage, action coordination, access and } \\
\text { accessibility). } \\
\text { For this study: } \\
\text { Technical dimension: Implementation of preventive and diagnostic measures and symptomatic treatment } \\
\text { of mild COVID-19 cases in a timely manner (according to scientific protocols). } \\
\text { Interpersonal dimension: Emotional support actions by healthcare providers to users and/or family } \\
\text { members in situation of social isolation. } \\
\text { Organisational dimension: Monitoring and follow-up actions of COVID-19 cases and continuity of care for } \\
\text { patients without COVID-19. }\end{array}$ \\
\hline
\end{tabular}

\section{Data sources}

For a broader scope search, multidisciplinary health sciences databases and grey literature will be used. The following databases will be accessed: VHL, PubMed, Scopus, Web of Science, CINAHL and Embase. For the grey literature, searches will be conducted on Google Scholar (government guidelines, manuals, reports, documents, books and congress proceedings), preprint repositories (SciElo Preprints, bioRxi and medRxiv) and specific databases for COVID-19 studies (WHO Global research on coronavirus disease, Cochrane Library, COVID-19 Open Research Dataset Challenge and Epistemonikos COVID-19).

\section{Step 3: study selection}

The study selection process for both the white and grey literature (identification, screening, eligibility and inclusion) ${ }^{32}$ will be presented in detail in the selection flowchart of the review. These steps will be conducted by two independent reviewers (CRDVS and RHL), and, in case of disagreement, a third reviewer (SACU) will be consulted to reach a consensus.

Identified studies will be grouped in the Mendeley reference manager and duplicates will be removed. The Rayyan software will be used during title and abstract analysis to assist blinding of reviewers. Potentially relevant studies will be retrieved in full and exported to a Microsoft Excel (V.2016) database. Full texts will be analysed in detail according to eligibility criteria, and reasons for excluding studies will be recorded and reported in the review.

The selection process of studies from the grey literature will follow Godin $e t a l,{ }^{33}$ and specific strategies will be conducted for searches on Google Scholar, preprint repositories and specific databases for COVID-19. The following terms will be combined: primary healthcare, telemedicine, information and communication technologies, healthcare quality and COVID-19. The terms and number of studies retrieved will be recorded for each search strategy and the identified studies will follow the proposed selection steps mentioned above. Results from Google Scholar will be classified by relevance and the first 100 studies will be included in the screening process. ${ }^{33}$

Studies will be selected if data on at least one quality of care dimension (technical, interpersonal, organisational) are provided, as defined in table 2. Reference list of the identified studies will also be consulted for potentially relevant studies.

Before data collection, a pilot test will be conducted with all authors to reduce bias and ensure an aligned selection process: each author will select a random sample of 25 titles and abstracts, and screening will be performed according to eligibility criteria. Afterwards, the team discuss discrepancies and perform any necessary changes to criteria and definitions. Screening will initiate only after reaching an agreement of $\geq 75 \%,{ }^{31}$ according to Fleiss' Kappa statistics. ${ }^{34}$

\section{Inclusion criteria}

The following full-text studies focusing on telemedicine in PHC during the COVID-19 pandemic, answering the study questions (table 1) and addressing at least one quality of care dimension (table 2) will be included: (1) primary studies, literature reviews, theoretical essays or brief communications; (2) grey literature, including preprints, guidelines, manuals, reports, government documents, books, dissertations, theses, and congress proceedings or other events of the academic community.

Filters related to time will not be applied to searches since search strategies will already contain descriptors 


\begin{tabular}{|c|c|c|}
\hline Stage & Start & Conclusion \\
\hline Pilot searches to substantiate the review protocol and define the search strategy & 2 September 2020 & 1 March 2021 \\
\hline Construction of the review protocol & 11 September 2020 & 13 March 2021 \\
\hline Protocol registration in the Open Science Framework & 18 March 2021 & 18 March 2021 \\
\hline Study selection & No & No \\
\hline Data extraction and coding & No & No \\
\hline Analysis and interpretation of results & No & No \\
\hline Consultation with stakeholders & No & No \\
\hline
\end{tabular}

and terms related to the COVID-19 pandemic. Language filters will also not be used and an external translator will perform necessary translations. Searches will be updated 1 week before submitting the study to a scientific journal.

\section{Exclusion criteria}

This review presents a wide scope of research questions; therefore, only publications with inconsistent results or not answering the research questions will be excluded.

\section{Step 4: data extraction and coding}

Data related to the included studies will be extracted by two independent reviewers (CRDVS and RHL) using a data extraction form created based on the $\mathrm{JBI}^{31}$ template and adapted by the authors. The following information of interest will be retained: study description (title, first author, institution, year, objectives, study design, sample/participants, funding) and data answering the research questions (country that used telemedicine, ICT type, impact on quality of care) (online supplemental appendix 3).

A pilot test will be conducted with all authors and the extraction form filled with three studies ${ }^{28}$ to ensure that all necessary data will be retained properly. If necessary, the form will be refined to align the extraction process. Any changes will be reported in detail in the scoping review. Any divergences between reviewers during extraction process will be resolved by a third reviewer (SACU). When necessary, first authors will be contacted to request additional or missing data.

Google Earth V.7.15 and TerraView V.4.2.2 software will be used to identify and geocode the studies.

\section{Step 5: analysis and interpretation of results}

Data will be summarised quantitatively or qualitatively, as appropriate. For quantitative analysis, descriptive statistics (absolute frequencies and percentages) will be performed using SPSS software, V.24 (IBM). Qualitative analysis will be conducted using thematic analysis. ${ }^{35}$

This stage will be divided into ${ }^{30}$ data analysis, exposure of the results linked to research questions, and implications for other research and services. All results will be discussed with the relevant literature. Evidence synthesis will be presented using tables, diagrams, thematic maps, and, if possible, a meta-analysis will be conducted. A narrative summary reporting how results are related to the review purpose and research questions will accompany the mapped data.

\section{Step 6: consultation with stakeholders}

This will be the last step of the review. ${ }^{30}$ After analysing and interpreting, preliminary results will be presented to a group of experts in telemedicine and ICTs in PHC. The procedure will include invitation via email explaining the stakeholder participation and, if accepted, all materials will be sent to the panel of experts. Two web conferences will be scheduled to discuss results.

This strategy aims to share preliminary study findings (knowledge transfer and exchange), obtain potentially relevant studies not included in the initial search and develop effective dissemination strategies and directions for future studies. ${ }^{30}$

\section{Patient and public involvement}

In this protocol, there was no involvement of patients and the public. Stakeholder participation in the consultation stage is part of the scoping review dissemination plans. Patients will not be involved.

\section{Ethics and results dissemination}

In this study, secondary sources of information (ie, studies published in scientific journals and grey literature) will be included.

Human involvement will take place at the stakeholder consultation stage and will have the main purposes of defining dissemination strategies and sharing preliminary results of the study.

\section{Ethical approval}

Approved by the Research Ethics Committee of the Faculty of Health Sciences of Cariri, Federal University of Rio Grande do Norte (CAAE: 47473121.3.0000.5568).

Results will be disseminated through publication in an open access scientific journal, international congress in the field of collective health, and other media such as academic and community newspapers.

In case of changing this protocol after publication, information regarding changes, proper justification and dates will be provided.

The stages of the ongoing review are shown in table 3 .

Acknowledgements The authors acknowledge the assistance provided by the Graduate Program in Health Sciences of the Federal University of Rio Grande do 
Norte and theCoordenação de Aperfeiçoamento de Pessoal de Nível Superior Brazil (CAPES) by the Finance Code 001 support.

Contributors SAdCU proposed the study and coordinated the elaboration of the protocol. CRDVS and MFT developed the protocol. CRDVS, RHL, OdGBJ, MF-T, RAA and SdACU participated in the discussion of the theoretical and methodological aspects of the study. CRDVS and RHL conducted the pilot searches to substantiate the search strategy. All authors reviewed the protocol and approved its final version for publication.

Funding The authors have not declared a specific grant for this research from any funding agency in the public, commercial or not-for-profit sectors.

Competing interests None declared.

Patient consent for publication Not required.

Provenance and peer review Not commissioned; externally peer reviewed.

Supplemental material This content has been supplied by the author(s). It has not been vetted by BMJ Publishing Group Limited (BMJ) and may not have been peer-reviewed. Any opinions or recommendations discussed are solely those of the author(s) and are not endorsed by BMJ. BMJ disclaims all liability and responsibility arising from any reliance placed on the content. Where the content includes any translated material, BMJ does not warrant the accuracy and reliability of the translations (including but not limited to local regulations, clinical guidelines, terminology, drug names and drug dosages), and is not responsible for any error and/or omissions arising from translation and adaptation or otherwise.

Open access This is an open access article distributed in accordance with the Creative Commons Attribution Non Commercial (CC BY-NC 4.0) license, which permits others to distribute, remix, adapt, build upon this work non-commercially, and license their derivative works on different terms, provided the original work is properly cited, appropriate credit is given, any changes made indicated, and the use is non-commercial. See: http://creativecommons.org/licenses/by-nc/4.0/.

\section{ORCID iD}

Cícera Renata Diniz Vieira Silva http://orcid.org/0000-0002-0928-8368

\section{REFERENCES}

1 World Health Organization. Rolling updates on coronavirus disease (COVID-19. Geneva: WHO, 2020. https://www.who.int/emergencies/ diseases/novel-coronavirus-2019/events-as-they-happen

2 World Health Organization. Coronavirus disease (COVID-19) pandemic. Geneva: WHO, 2020. https://www.who.int/

3 World Health Organization. Novel Coronavirus (2019-nCoV) situation report - 11. Geneva: WHO, 2020. https://www.who.int/docs/defaultsource/coronaviruse/situation-reports/20200131-sitrep-11-ncov.pdf? sfvrsn=de7c0f7 4

4 World Health Organization. Novel Coronavirus (2019-nCoV) situation report - 51. Geneva: WHO, 2020. https://www.who.int/docs/defaultsource/coronaviruse/situation-reports/20200311-sitrep-51-covid-19. pdf?sfvrsn=1ba62e57_10

5 World Health Organization. WHO coronavirus disease (COVID-19) Dashboard. Geneva: WHO, 2020. https://covid19.who.int/table

6 Zhu N, Zhang D, Wang W, et al. A novel coronavirus from patients with pneumonia in China, 2019. N Engl J Med 2020;382:727-33.

7 World Health Organization. Proceedings and reports relating to international quarantine: supplement to official records No. 63: eighth World health assembly. WHO: Geneva, 1955. https://apps.who. int/iris/bitstream/handle/10665/85663/Official_record64_eng.pdf? sequence $=1$ \&isAllowed $=y$

8 Taghrir MH, Akbarialiabad H, Ahmadi Marzaleh M, Marzaleh MA. Efficacy of mass quarantine as leverage of health system governance during COVID-19 outbreak: a mini policy review. Arch Iran Med 2020;23:265-7

9 Phua J, Weng L, Ling L, et al. Intensive care management of coronavirus disease 2019 (COVID-19): challenges and recommendations. Lancet Respir Med 2020;8:506-17.

10 Smith AC, Thomas E, Snoswell CL, et al. Telehealth for global emergencies: implications for coronavirus disease 2019 (COVID-19). J Telemed Telecare 2020;26:309-13.

11 Kadir MA. Role of telemedicine in healthcare during COVID-19 pandemic in developing countries. Telehealth and Medicine Today 2020;5:1-5.
12 Elson EC, Oermann C, Duehlmeyer S, et al. Use of telemedicine to provide clinical pharmacy services during the SARS-CoV-2 pandemic. Am J Health Syst Pharm 2020;77:1005-6.

13 Ekeland AG, Bowes A, Flottorp S. Effectiveness of telemedicine: a systematic review of reviews. Int J Med Inform 2010;79:736-71.

14 World Health Organization. Data telemedicine: opportunities and developments in member states: report on the second global survey on eHealth. Geneva: WHO Library Cataloguing-in-Publication, 2009. https://apps.who.int/iris/bitstream/handle/10665/44497/ 9789241564144_eng.pdf?sequence=1\&isAllowed=y

15 World Health Organization. A health telematics policy in support of WHO's Health-For-All strategy for Global Health Development. Geneva: World Health Organization, 1998. https://apps.who.int/iris/ bitstream/handle/10665/63857/WHO_DGO_98.1.pdf?sequence=1\& isAllowed $=\mathrm{y}$

16 Wosik J, Fudim M, Cameron B, et al. Telehealth transformation: COVID-19 and the rise of virtual care. J Am Med Inform Assoc 2020;27:957-62.

17 Mann DM, Chen J, Chunara R, et al. COVID-19 transforms health care through telemedicine: evidence from the field. J Am Med Inform Assoc 2020;27:1132-5.

18 Ting DSW, Carin L, Dzau V, et al. Digital technology and COVID-19. Nat Med 2020;26:459-61.

19 Pappot N, Taarnhøj GA, Pappot H. Telemedicine and e-health solutions for COVID-19: patients' perspective. Telemed J E Health 2020;26:847-9.

20 Sarti TD, Lazarini WS, Fontenelle LF. Qual O papel dA Atenção Primária Saúde diante dA pandemia provocada pela COVID-19? Epidemiol Serv Saúde 2020;29:e2020166.

21 Moazzami B, Razavi-Khorasani N, Dooghaie Moghadam A, et al. COVID-19 and telemedicine: immediate action required for maintaining healthcare providers well-being. Journal of Clinical Virology 2020;126:104345.

22 Jiménez-Rodríguez D, Santillán García A, Montoro Robles J, et al. Increase in video consultations during the COVID-19 pandemic: Healthcare professionals' perceptions about their implementation and adequate management. Int J Environ Res Public Health 2020;17:5112.

23 Donabedian A. An introduction to quality assurance in health care. New York: Oxford University Press, 2003.

24 Champagne F, Hartz Z, Brousselle A. A apreciação normativa. In: Brousselle A, Champagne F, Contandriopoulos AP, et al, eds. Avaliação: conceitos e métodos. Rio de Janeiro: Editora Fiocruz, 2011: 77-94.

25 Donabedian A. Exploration in quality assessment and monitoring. Ann Arbor: Health Administration Press, 1980.

26 Latifi R, Doarn CR. Perspective on COVID-19: finally, telemedicine at center stage. Telemedicine and e-Health 2020;26:1106-9.

27 Tricco AC, Lillie E, Zarin W, et al. PRISMA extension for scoping reviews (PRISMA-ScR): checklist and explanation. Ann Intern Med 2018;169:467-73.

28 Peters MDJ, Marnie C, Tricco AC, et al. Updated methodological guidance for the conduct of scoping reviews. JBI Evid Synth 2020;18:2119-26.

29 Arksey H, O'Malley L. Scoping studies: towards a methodological framework. Int J Soc Res Methodol 2005;8:19-32.

30 Levac D, Colquhoun H, O'Brien KK. Scoping studies: advancing the methodology. Implementation Sci 2010;5:69.

31 Peters MDJ, Godfrey C, Mclnerney P. Chapter 11: Scoping reviews. In: Aromataris E, Munn Z, eds. JBI manual for evidence synthesis. Adelaide: JBI, 2020. https://synthesismanual.jbi.global

32 Shamseer L, Moher D, Clarke M, et al. Preferred reporting items for systematic review and meta-analysis protocols (PRISMA-P) 2015: elaboration and explanation. BMJ 2015;349:g7647.

33 Godin K, Stapleton J, Kirkpatrick SI, et al. Applying systematic review search methods to the grey literature: a case study examining guidelines for school-based breakfast programs in Canada. Syst Rev 2015;4:1-10.

34 Fleiss JL. Measuring nominal scale agreement among many raters. Psychol Bull 1971;76:378-82.

35 Moher D, Liberati A, Tetzlaff J, et al. Preferred reporting items for systematic reviews and meta-analyses: the PRISMA statement. PLoS Med 2009;6:e1000097.

36 Oh H, Rizo C, Enkin M. What is eHealth: a systematic review of published definitions. J Med Internet Res 2005;41:32-40.

37 Belloni ML. O que é mídia-educação? Coleção polêmicas do nosso tempo. Campinas, SP: Autores Associados, 2005. 